\title{
Inositol 1,4,5-Trisphosphate
}

National Cancer Institute

\section{Source}

National Cancer Institute. Inositol 1,4,5-Trisphosphate. NCI Thesaurus. Code C580.

A phosphatidylinositol with phosphate covalently bound in the 4 and 5 positions of the inositol group. Inositol 1,4,5-trisphosphate acts as an intermediate in the IP3/DAG pathway, hydrolyzed by phospholipase C and liberating diacylglycerol and PIP2, which activate Protein Kinase $\mathrm{C}$ and calcium release from the endoplasmic reticulum, respectively. 